\title{
JANSSEN, C. R.: Alnus as a disturbing Factor in Pollen Diagrams
}

It is commonly accepted that percentages of pollen in a pollen diagram do not express the exact composition of forests in earlier times. This inaccuracy is due to several factors, for instance the different quantities of pollen produced by plants, the distance of transport etc. A pollen diagram tells us only the change in pollen rain on the locality where we collected soil samples. In studying a pollen diagram we find a close relation between the variations in the percentages of a certain species and the area occupied by this species in the vegetation. When the percentage of pollen of a species increases, we conclude generally that the relative area occupied by this species in the vegetation increases too. However, such a connection might be doubted. The variety of factors controlling the dispersion of pollen is so great that the interpretation of a pollen diagram often meets - with great difficulties. The connection between pollen rain and the composition of the vegetation is a simple one in the cases where we are dealing with a region of uniform vegetation. A diagram taken from a region in which the vegetation varies from place to place has to be regarded with some caution. Unfortunately such a heterogenity of the vegetation exists on the very place, where we want to compose a pollen diagram.

The pollen rain which falls into a bog arises from two sources: a pollen rain from the local vegetation of the bog itself and one from the surrounding vegetation. When we are dealing with great bogs, the pollen produced by the vegetation of the bog itself will be mostly that of herbaceous plants, shrubs, and spores of the Bryophyta and the Pteridophyta. It is the rule rather than the exception that the bog will be treeless. The tree pollen in such a bog mostly takes its origin from the surrounding forests. It is a fortunate circumstance in a diagram that pollen of trees is separated from other pollen. However, one exception is seen in the way in which Iversen composes a diagram for late glacial times. This method, commonly used for late glacial times, embraces a pollen sum not only containing trees but also some herbaceous plants. The origin of the latter can, with some certainty, be accepted as from outside the bog. Therefore the local vegetation of the bog does not influence the percentages of tree pollen. The pollen sum thus comprises pollen of plants which grow under the same biotic conditions.

However, there exist diagrams the pollen sum of which contains pollen of tree species not growing under the same conditions. One of the tree species belonging to the bog itself may show pollen variations which are independent of the tree species outside the bog. These variations, therefore, are reality only for the species growing in the bog and should not be applied to those outside. By adding the pollen of this species to the pollen sum we have the disadvantage that the species strongly influences the percentages of other tree species. In order to interpret the history of the forests it will be necessary to remove such a tree from the treepollen sum. It -will be clear that we must know with some certainty whether a tree belongs to the bog itself.

Indeed there are diagrams which show this phenomenon very clearly. Figure 1 gives a diagram from a bog in the southern part of the province of Limburg. The bog is situated at the bottom of the valley of the Geleen river near Nuth. The 
diagram shows very high percentages of Alnus (average about $80 \%$ ). It is not very difficult to explain these high percentages, because in the present the vegetation of the bog is an Alnetum. It is known that Alnus likes wet places and these very places are fairly rare in a hilly landscape like Limburg. Alnus does not occur on the surrounding slopes.

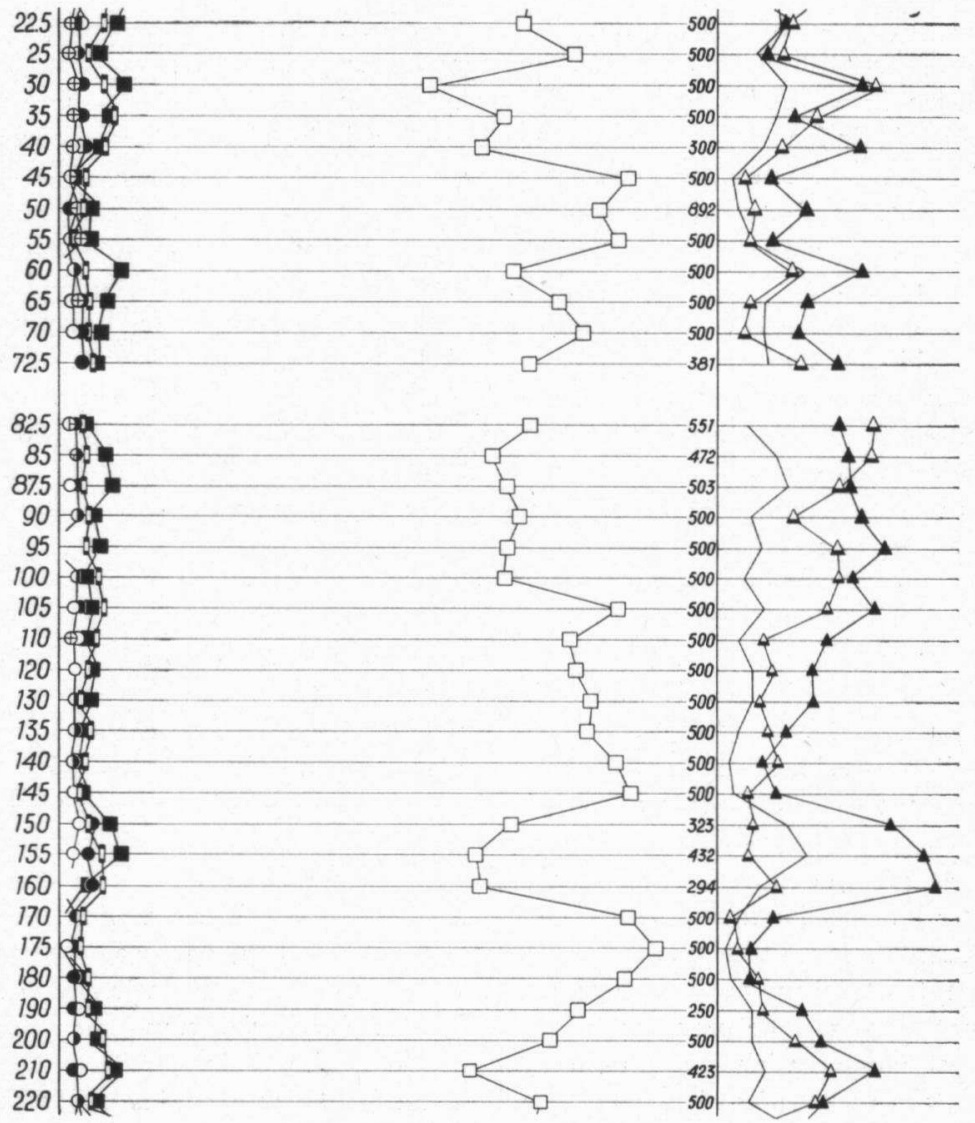

Fig. 1. Pollen diagram of Nuth, including Alnus in the tree-pollen sum.

The tree following Alnus in importance in the diagram is Fagus, a tree which grows only on the drier slopes. In the diagram we notice little maxima of Fagus on depths of $60,95,160$ and $210 \mathrm{~cm}$. However on the same depths Alnus shows a slight decrease. Therefore it may be said that the maxima of Fagus are artifacts, caused by a local decrease of Alnus. The constancy of the Fagus curve is visible in figure 2, in which Alnus has been removed from the tree pollen sum.

On the other hand, an increase in Alnus flattens actually existing maxima of trees on the slopes. If we take Alnus in the tree pollen sum it is possible to draw a wrong conclusion about the history of the forests. 
The necessity of removing Alnus does not exist if the Alnus curve is a constant one. The curves of the other trees are not influenced in that case. As the absolute value of percentages is of no importance, removal of Alnus is necessary even when the Alnus curve is a very high one. A disadvantage of removing Alnus is the necessity of counting more pollen for each spectrum, especially when Alnus occurs in high percentages. If the peat is containing little pollen, the remaining pollen

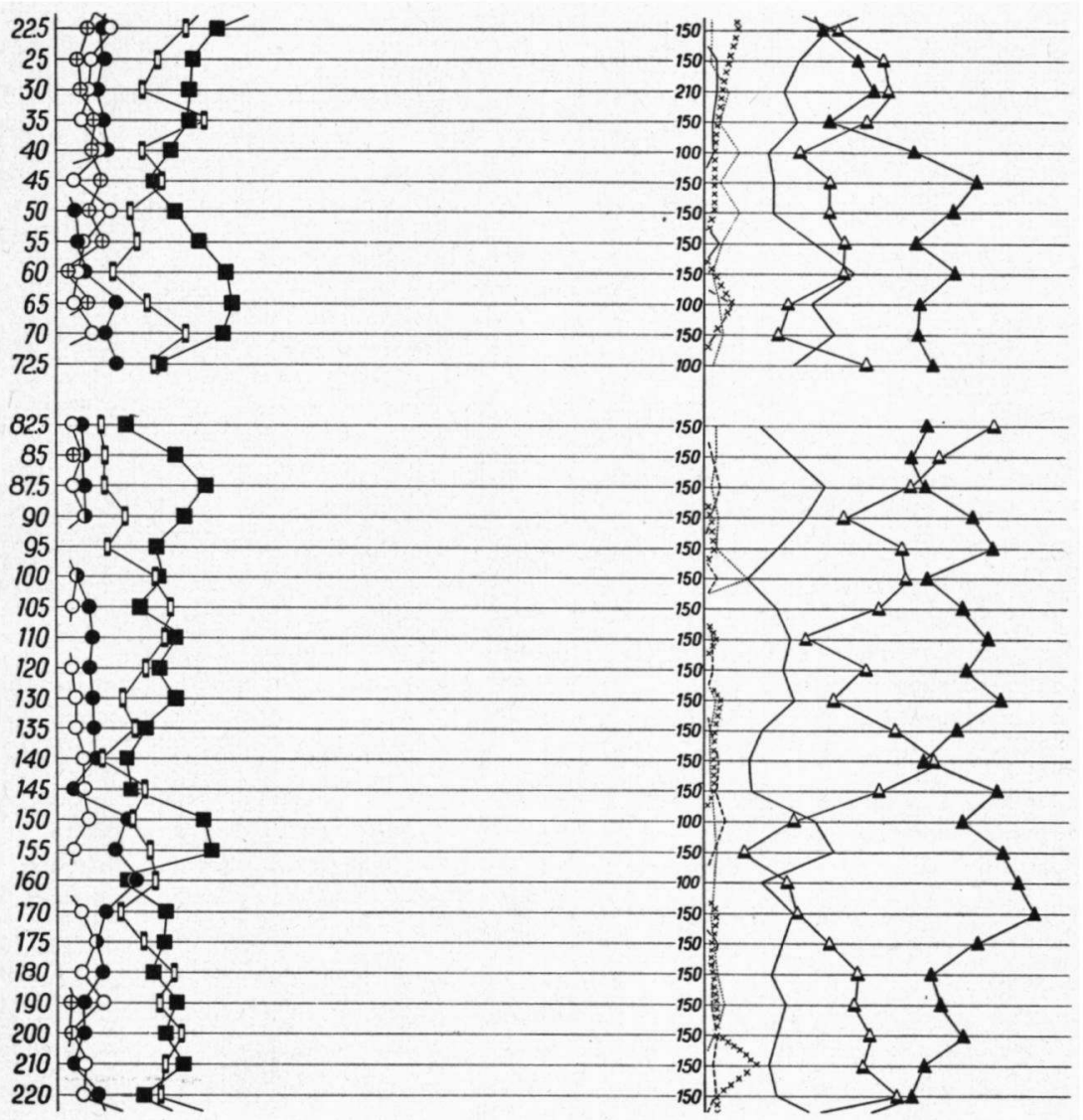

Fig. 2. Pollen diagram of Nuth, excluding Alnus from the tree pollen sum.

sum becomes too small to calculate meaningfull percentages. The same explanation given for Alnus holds for Salix. As Salix in the diagram shows no variations it has not been removed.

The method of removing Alnus should not be a general rule. It seems to me that it may be done only in regions where it is clear that the trees growing in the bog are of a different species from those outside. It is possible that, when applied to large bogs the method will give erroneous results, because either such bogs are treeless or Alnus grows outside the bog as well. In a recent publication Fries (1958) removed Alnus and Salix too in consideration of the supposed local 
overrepresentation of two genera. I do not know whether in Väster Götland Alnus and Salix are restricted to small areas like in South Limburg. In any case in some of his diagrams the curves show the same dependence on the curve of Alnus. Anyhow, in a hilly landscape like South Limburg the removal of Alnus is nearly a necessity.

Finally it has to be said that comparison with other diagrams in which Alnus has not been removed may become difficult. Concerning the trees taken into the tree-pollen sum, the reverse happened in the past with Corylus, however with other considerations (FAEGrI and IVERSEN, 1950; Jonker, 1952). Indeed the comparison of diagrams with tree-pollen sums containing different tree pollen is difficult. When we want to compose a diagram in a different manner from the usual, we must give a "normal" diagram as well.

The herbs and the remaining parts of the diagram will be discussed in a later paper.

\section{REFERENCES}

FAegri, K. and J. Iversen. 1950. Text-book of modern Pollen Analysis, Copenhagen: 68.

Fries, M. 1958. Acta Phytogeog. Suecica 39.

JONKER, F. P. 1952. Taxon 1 (6): 89. 